\title{
The Differential Attainment Rate among Latina Students: A Comparative Analysis of Recent Trends in Educational Achievements across Gender between 2005 and 2020
}

\author{
Enrique S. Pumar
}

Citation: Pumar, E.S. The Differential Attainment Rate among Latina

Students: A Comparative Analysis of Recent Trends in Educational Achievements across Gender between 2005 and 2020. Sustainability 2021, 13, 13399. https://doi.org/10.3390/ su132313399

Academic Editor: Marc A. Rosen

Received: 8 September 2021

Accepted: 20 November 2021

Published: 3 December 2021

Publisher's Note: MDPI stays neutral with regard to jurisdictional claims in published maps and institutional affiliations.

Department of Sociology, Santa Clara University, Santa Clara, CA 95053, USA; epumar@scu.edu; Tel.: +1-408-554-4780

\begin{abstract}
Grounded on educational achievement data between 2005 and 2020 from the Digest of Educational Statistics, this paper makes the point that despite considerable academic achievements, Latinas continue to underperform when compared to women of other races and ethnicities while concurrently outscoring Latinos. When differential attainment rates are disaggregated among coethnics Latinas, there is enough evidence to suggest that national development and quality of life, particularly the rate of women's participation in secondary schooling, condition the association between ethnicity, gender, and educational achievement. Besides contributing to the literature and methodology of transition rates, the research supports the advocacy for more inclusive and equitable educational attainment announced in Sustainable Development Goal 4 and it suggests that more attention should be paid to how transnationalism affects education.
\end{abstract}

Keywords: Latinas; educational attainment; achievement; women graduation rates; educational transition rates

\section{Introduction}

Support for educational attainment policies continues to take precedence worldwide regardless of gender, personal wealth, or national origin. The United Nations, for instance, counts inclusive and equitable educational programs as one of its Sustainable Development Goals. In the United States, family investment in education measures in the trillions. Many migrant families trek around the globe to take advantage of primary and secondary schooling and for a chance to compete for admission at world-class universities, among other reasons [1]. Additionally, among Latino/Hispanic families, the relative social mobility and status attainment brought along by education is synonymous with personal achievement. The fact that educational aspirations materialized asymmetrically has compelled researchers to critically question the extent to which the dispersion of educational achievement in the United States and other nations supports UN policy recommendations to ensure equal educational opportunities.

This paper analyzes data from the Digest of Educational Statistics [2] published by the United States Department of Education National Center for Educational Statistics (NCES) to identify trends in the differential attainment rates among the Latina student population compared with other ethnic groups.

Many studies compare the performance of ethnic groups without disaggregating educational attainment trends by gender or national origins [3]. The case of Latinas illustrates the complexities associated with social inequality and supports the drive to amend gender disparities and promote more inclusive policies. The educational data shows that different attainment rates must be disaggregated by such social attributes as gender, race, ethnicity, and ethnic nationality. Latinas generally outperform their male counterparts in school but fall short of other peers across ethnic groups [4]. This group also shows fluctuation in educational attainment according to national origins. One compelling reason to examine 
data from the United States is that the country is in the midst of one of the most significant demographic shifts in its history [5]. An examination of educational accomplishments presents not just a barometer of the performance of schools and educators but also essentially illustrates how opportunities continue to be racialized in a leading industrial nation.

In particular, the paper points out that despite considerable educational achievements among Latinas in recent years [6], measured by graduation rates, the achievement gap among Latina students continues to be primarily driven by what Vlaardingerbroek and Ros [7] called educational transition rates. Considering the impact of labor market opportunities today, the weight of transition rate calculations is most relevant when measuring the transition from secondary to post-secondary school. Contrary to Portes and Rumbaut's [8] argument, when transition rates are disaggregated by nationality, there is evidence to suggest that quality of life in the countries of origin, especially the number of women with at least some secondary education, conditions the relation between ethnicity and attainment. Ultimately, one of the primary goals of this study is to identify other reasons behind the persistent achievement gap besides those already noted by Zhang [9], the effects of institutional arrangements documented by Nguyen et al. [10], and the social and economic factors exposed by Madrid [11] in his comprehensive review of the literature. These studies and many others analyze how domestic forces shape educational outcomes and disregard transnational effects.

\section{Literature Review}

Explaining graduation trends over the last few decades has taken considerable effort among social scientists. Starting with James Coleman's groundbreaking Equality in Educational Opportunity, a nationwide study published in 1966, scholars developed an interest in documenting the dispersion of opportunities, measured by school completion, to explain educational success and estimate school quality. The Coleman Report, as the mammoth study came to be known, was one of the first national studies to disaggregate student performance by race to document the legacy of decades of school segregation. Coleman's evidence-based approach also demonstrated how rigorous empirical findings and inquiries generate parsimonious and robust explanatory statements that impact national educational policies, uprooting the sociology of education field. In concrete terms, the massive data captured by Coleman were instrumental in advocating for the urgent need to formulate more inclusive policies that would reduce racial and ethnic disparities. After his report, it became abundantly clear that when it comes to understanding achievement, the strains between three levels of analysis [12], roughly corresponding to the micro, meso, and macro, remain undeniable.

Micro-level explanations of achievement emphasize the role of agency, especially the extent to which parental perseverance and resilience motivate students to overcome structural impediments associated with schooling [13]. Rumbaut [14] persuasively argues that a case in point is the sense of obligation first-generation students develop to compensate for their parent's devotion to sustain the family and support the children in school regardless of human capital. Although many studies would confirm Garry Hornby's [15] bold assertion that "it is clear that parental involvement is of considerable importance to children's achievement in schools," this line of research also points to several hindrances that condition the extent of parental commitments. For instance, Suarez-Orozoco et al. [16] and Schen [17] stress the effects of family separation on the psychological well-being of immigrant students and their parents [18]. Vega et al. [19] found that often among lowincome families, work schedules, transportation hurdles, and strained financial resources often interfere with parental desires to get more involved in school-related functions and academic activities. Finally, Zarate [20] argues the importance of maintaining frequent and meaningful parent/teacher communication to assure successful progress in schools.

The second line of research, more prevalently argued by educators and student service providers, emphasizes how institutional arrangements, practices, and socialization exponentially augment student achievement. The University of South Carolina 
Student Success Center is not alone when it brazenly proclaims on its webpage that "with the right resources and relationships, there is no end to what we can achieve". (https://www.sc.edu/about/offices_and_divisions/student_success_center/index.php (accessed on 6 August 2020)). Multiple studies have also demonstrated how, particularly among immigrant populations, connecting to role models, caring advisors, and mentors has positively impacted the chances of graduation. As we know all too well, dedicated high school counselors usually provide timely information to secure financial assistance opportunities, strategies to complete admission applications, and even crucial insights to help select the most suitable colleges and universities. The ongoing research also demonstrates that access to faculty of color who can function as dedicated role models improves the chances of completing school. After conducting an extensive review of the literature, Alcocer and Martinez [21] (p. 2) concluded, "Mentoring is critical at all levels of development, and research affirms the need for these relationships at every stage in the professional career of underrepresented minorities". Unfortunately, recruiting a diverse faculty has proven to be one of higher educational institutions' most pressing challenges today. According to a nationwide report issued by the Pew Research Center in 2019 [22], university faculty has increasingly become more diverse in the last two decades but still lags behind students. In 2017, just $19 \%$ of professors, $24 \%$ of associate professors, and $27 \%$ of assistants identified themselves as faculty of color compared to $81 \%$ of professors, $76 \%$ of associate professors, and $73 \%$ of assistant professors who self-identified as white. According to the Pew Center report, this racial imbalance is particularly evident among Latino/a faculty whose growth remained fairly flat between 1997 and 2017 [22].

The passing of the No Child Left Behind (NCLB), Race to the Top, and other federal initiatives to reduce the achievement gap is at least an implicit recognition by federal authorities that the quality of schools and teachers, as well as the relevance of the curriculum, has a decisive effect on student outcomes. Whether the federal legislation proposes to promote more effective schooling by incentive grants, market competition, or sanctions, the overriding assumption behind these policies is that schools that do not meet standards of excellence fail their student population. The drive to promote programmatic assessment and faculty accountability in higher education is often grounded on this premise.

Finally, macro-social accounts band together various explanatory positions that underscore the innumerable weight of ecological obstacles, including the social stigmatization, clustering, and biases many students of color must overcome to succeed in schools from years of prejudice and discrimination. The substance of this literature is too rich to summarize here. Still, proponents of this level of analysis seem to agree that structural conditions continue to affect learning outcomes while also imposing elevated transaction costs to, in effect, derail the chances for academic success. In a pointed critique of the cultural literacy movement published in The Guardian newspaper in 2014, Tait Coles forcefully argues that to make teaching more relevant, and therefore more effective for the growing number of students who encounter oppression, instructors must integrate without hesitation the effects of structural social conditions into their pedagogy. Coles [23] emphatically defends his position, proposing that "teacher cannot ignore the context, cultures, histories, and meanings that students bring to their schools". For inclusive opportunities to stand a chance at all, the goal is to refrain from converting schools into what Paolo Freire [24] cogently calls "acts of depositing".

As this scanning review of the literature and the overview of notable books such as Mehta and Davis's [25], Sadovnick and Coughlan's [26], and Karabel and Halsey's [27], among several others, demonstrates, the implications of educational inequalities in our society today are no leisure task. Many questions remain unanswered, and none are more pressing than to try to discern the reasons behind the fluctuation of attainment rates among and within ethnic groups [28]. Beyond this important consideration, it is also critical to reassess how educational attainment is usually operationalized in the literature. Outputs seem very different when those who successfully transition to college are considered instead of the graduation data. Regardless of levels of analysis, education research still 
seems biased towards explaining achievement according to completion rates without contemplating the possibility that not all graduating students continue their education after commencement. The dreadful fact that only a portion of students who finish high school enroll in universities, or even community colleges, is all too common to ignore. Calculating transition rates constitutes a fertile research ground to begin to address the important misconceptions that characterize educational achievement, especially when the research accounts for gender.

\section{Methods}

Transition-rate calculations capture the percentage of graduating students who enroll in higher grade levels. Table 2 compares transitions rates as the percentage of high school graduates enrolled in college. Without disregarding asymmetrical historical educational opportunities [7], transition-rate calculations posit many analytical advantages to researchers and policymakers. For one, it helps us assess how social differentiation impacts variations in educational achievements. Without trivializing the weight of discriminatory structural practices [29], transition rates also measure fluctuations longitudinally and comparatively. Most importantly, considering that not all students cleared for graduation move on to pursue other educational opportunities [30], accounts of academic success are also a reliable indicator of how institutional cultures cultivate resilience and the critical appreciation for lifelong learning despite limited family resources or palpable structural barriers. Finally, graduation figures might be skewed by social promotion and other exogenous considerations that are usually minimized by competitive admission processes.

The paper also contributes to the emerging literature on transition by amending four of the most basic premises in the research published by Vlaardingerbroek and Ros (1990). First, regarding research design, rather than focusing on analyzing data from a single discipline, this study examines the aggregated measurement of school completion without discerning specific fields. Aggregate data more accurately predict group success across the board. Second, whereas the Vlaardingerbroek and Ros study compares longitudinal performance among five developing nations, the research design in this paper contrasts four social groups according to race, ethnicity, and gender in a single case study to control spuriousness. In addition, the paper does not measure educational transition by enrollment figures alone, as in Vlaardingerbroek and Ros's [31] calculations. Instead, it combines graduation data with college enrollment because college graduation figures are a function of the college experience, not a measurement of transition from secondary to post-secondary schooling. Finally, the paper suggests that transnational factors also condition educational achievement.

In terms of research design, the paper follows two versions of the within-group comparison method. First, the analysis contrasts the performances of four major ethnic and racial groups in five-year intervals between 2005 and 2020. Then, to determine variations within a single ethnic group, Table 3 correlates college enrollment data in 2010 and 2018 from among 13 of the largest Latina communities residing in the United States with the human development index (HDI), a United Nations indicator of national progress and quality of life, and the educational achievement of women. The data collected for these comparisons came from secondary sources such as the US government's and United Nations Development Program's (UNDP) annual Human Development Report. Standard percentage change calculations determined longitudinal dispersions. The standardization of measurements permits provocative comparisons of achievement trends for more than a decade. In addition, all the data follow the conventional usage of percentage points and percentage change, a standard computation in educational policy studies. Finally, by focusing on the United States, a nation with multiple educational opportunities, this study assesses how success is structured. 


\section{Results}

\subsection{Measures of Dispersion over Time}

To further reflect on the completion and achievement in education and the merits of exploring a transition-rate approach, the paper first examines the secondary and postsecondary graduation of Latinas by race and ethnicity. This will be followed by a discussion of how transition data provide a more comprehensive view of educational success. Finally, I propose disaggregating college graduation among the top Latina nationalities in America to discern the variations in achievement rates within the group.

The data captured in Table 1 reveal the complexities behind educational inequality over time. One glaring conclusion from these scores is that Latina students have made enormous strides since 2005, despite having one of the lowest overall attainment rates among the four major ethnic groups represented in the table. The gains made by Latina students are more impressive with regards to high school, associate degrees, and college graduations as measured by the percentage change between 2005 and 2020, where their achievement was well above the averages from other gender groups by more than 10 percentage points. Not surprisingly, the margin of success among Latinas decreased substantially in college and graduate school, where Latina students only showed modest improvements, as the diversity and inclusion literature argues. In college completion, Latinas exceeded the gains of other groups in terms of overall progress in the graduation rate since 2005, with whites and African Americans closely behind. This was not the case at the graduate level, however, where Latinas showed one of the lowest rates of attainment and fell noticeably behind, especially when compared with Asian female students.

Table 1. Educational attainment by race/ethnicity among women between 25 and 29 years old from 2005 to 2020.

\begin{tabular}{cccccc}
\hline Degree Completion & $\mathbf{2 0 0 5}$ & $\mathbf{2 0 1 0}$ & $\mathbf{2 0 1 5}$ & $\mathbf{2 0 2 0}$ & $\begin{array}{c}\text { Percentage Change } \\
\text { 2005-2020 }\end{array}$ \\
\hline High school & & & & & 3 \\
Whites & 94 & 94 & 96 & 97 & 9 \\
Blacks & 87 & 91 & 93 & 96 & 26 \\
Latinas & 63 & 74 & 79 & 89 & 2 \\
Asians & 95 & 94 & 95 & 97 & 14 \\
Associate's degree & & & & & 13 \\
Whites & 48 & 54 & 59 & 62 & 9 \\
Blacks & 30 & 35 & 37 & 43 & 12 \\
Latinas & 19 & 26 & 29 & 40 & 12 \\
Asians & 69 & 63 & 71 & 78 & 10 \\
Bachelor's degree & & & & & \\
Whites & 38 & 42 & 47 & 50 & 4 \\
Blacks & 21 & 23 & 25 & 33 & 3 \\
Latinas & 12 & 17 & 19 & 27 & 3 \\
Asians & 61 & 56 & 65 & 71 & 12 \\
Master's or higher & & & & & \\
Whites & 9 & 9 & 12 & 13 & 7 \\
Blacks & 4 & 6 & 7 & 6 & 26 \\
Latinas & 3 & 4 & 4 & 22 & 21 \\
Asians & 14 & 21 & & & \\
\hline
\end{tabular}

Note. Tables 104.20 of DES. Asian Americans include Pacific Islanders. All percentages were rounded off.

When the completion rate was measured yearly, Latinas continued to score the lower than any other group. Another disturbing conclusion is an inverse trend when correlating levels of education and attainment over time. Simply put, the rate of achievement among students of color decreases as the level of schooling increases. This trend not only impacts educational success but also translates into the earning potential of these groups [32]. In 2019, the median household income of the two top graduate student achievers was also the highest, USD 98,174 for Asians and USD 75,057 for whites. On the other hand, 
the net family income for African Americans was just USD 45,438 and for Latinos USD 56,113 , according to figures released by the Census Bureau and also by Semega et al. [33]. The literature on intersectionality has documented the bias embedded in stratified labor markets.

Another dimension of inequality is reflected in the inevitable comparison across gender. Figure 1 shows the trends in graduation rates between Latinos and Latinas according to grade level. For this comparison, the graduation rates of both genders were averaged by grade level in 2005, 2010, 2015, and 2020. This comparison shows that although Latinas consistently attained lower than other female groups, as Table 1 illustrates, they achieved higher than men across the board regardless of level of education. Both groups show a similar downward trend as years of schooling increased, and the margin of difference never surpassed a 10-point spread between Latinas and Latinos. However, although the graduation margin of both groups was only $2 \%$ in high school, it increased to $7 \%$ at the associate level and $6 \%$ at the graduate level, an indication that Latinas are more successful in school than their Latino counterparts. Despite showing higher educational attainment, Latinos tend to earn more than Latinas [34]. The US Bureau of Labor Statistics reports that in 2020, Latinas earned a median weekly salary of USD 722, whereas Latinos cashed in USD 823, a difference of more than USD 100.

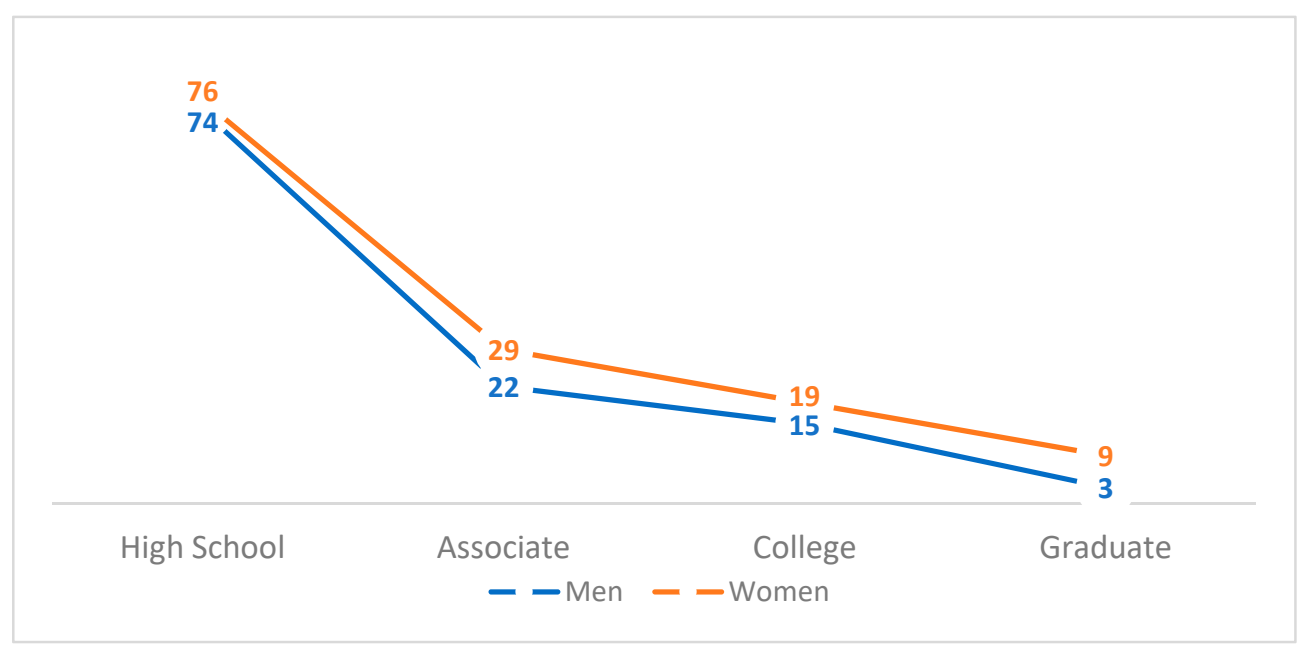

Figure 1. Average graduation rates for Latinos and Latinas by grade levels between 2005 and 2020.

\subsection{Educational Transition Rates}

A more concerning finding is represented in the transition between grade levels, or what the paper refers to as the transition rates, captured in Table 2. Educators refer to transition rates as the percentage of graduates who enroll in the next grade level. Table 2 expounds upon the number of female high schoolers who moved on to college. The paper took this measure because of the significance of college graduation and the amount of effort college and universities dedicate to recruiting and retaining underrepresented students. The percentages in Table 2 represent the enrollment figures of female students stratified by race and ethnicity. Some attrition between grades is always expected but transitioning from high school to college is more impactful than ever. In addition, the fact that transition rates are consistently stratified over time is another indication that the aspirations and opportunities of many students continue to be racialized in American society. Along with African American students, the transition rate of Latinas remains alarmingly low and below the rates of whites and Asian women. Except for 2015, Latinas and African American students transitioned apart. On average, in 2020, about half of Latina high school graduates enrolled in college, which meant a rate of decline of about 3\% since 2005. In contrast, African Americans displayed the smallest drop of all four groups. 
Table 2. Transition rates. Percentage of Latinas and other race/ethnic high school graduates enrolled in college between 2005-2020.

\begin{tabular}{cccccc}
\hline & 2005 & 2010 & 2015 & 2020 & $\begin{array}{c}\text { Percentage Change } \\
\text { 2005-2020 }\end{array}$ \\
\hline White & 49 & 49 & 47 & 46 & -3 \\
Black & 44 & 45 & 39 & 43 & -1 \\
Latina & 48 & 49 & 52 & 45 & -3 \\
Asian & 64 & 63 & 66 & 61 & -3 \\
\hline
\end{tabular}

Note. Data are presented as a percentage of high school graduates enrolled in college. High school graduation figures came from Table 104.20 and college enrollment from Table 302.60 in DES.

Besides impacting income, educational attainment today is also considered one of the most effective vehicles to break the cycle of poverty that has punished communities of color since at least the early 1960s. In 2019, the poverty rate among Latinos/Hispanics more than doubled compared to that of whites and Asian families, a rate only surpassed by African Americans. According to estimates calculated by Broady and Hershbein [35] of The Brooking Institute, the earning potentials of individuals holding a college degree in 2018 are reflected in the median salary of USD 68,000 as opposed to USD 49,000 for associate degrees. They conclude that college graduates still earn much more across the board than the median earnings of high school graduates in all majors studied. When earning potentials are added to the demands for knowledge workers, it is safe to conclude that a transition at this level of schooling is categorically more critical today than ever in our nation's history to offset the effects of post-Fordism. As if economic incentives were not enough, the COVID-19 pandemic has also amplified the public health effects of professional stratification. Individuals in flexible occupations that require at least a college degree are fundamentally less likely to be exposed to the impact of the pandemic. Latinos/Hispanics, who constitute about $18 \%$ of the US population, totaled about $28 \%$ of the COVID-19 cases nationwide, according to the Centers for Disease Control and Prevention (CDC) data tracker.

An analysis of high school graduates enrolled in college between 2005 and 2020 demonstrates how the dimensions of educational inequality fluctuate according to how achievement is measured. On the one hand, the number of Latinx students holding academic degrees from high school and beyond saw an overall increase after 2005, albeit with a modest rate in graduate degrees earned. However, when these numbers are contrasted with the percentage of high schoolers who transition to college, the picture is much more sobering. Only 4 out of 10 and about 3 out of 10 finished their associate's and college degrees, respectively. In short, transitions rates demonstrate that the meaningful educational progress among all Latina students cluster around the early grades, leaving them more vulnerable to combat their economic conditions after graduation. In this sense, transition numbers present a more accurate predictor of academic success and another depiction of inequality. Along with the trends in graduation, transition figures confirm that another factor conditioning inequality is grade level. The inequality patterns witnessed as education progress are caused, at least in part, by the amount of attrition between grades.

\section{Discussion \\ Graduation Rates and National Development}

The breakdown and consequences of college achievement displayed thus far have puzzled educators and pundits for decades. To depict this baffling dispersion, Table 3 breaks down college enrollments in 2010 and 2018 by nationality among the top Latina groups residing in the United States. Although it is well known that no two migration experiences are fully comparable, paring co-ethnics controls for language, cultural factors, identity, and other attributes that may condition success in school [36]. Table 3 summarizes preliminary findings from one of my pilot research studies, which attempted to assess the extent to which the levels of national development among sending societies impact the 
incorporation of migrants. The research about differential educational attainment rates thus far focuses primarily on the effects of schools, families, and communities on student performances, as the literature review in this paper demonstrates. On the other hand, my research explores the legacy of development and quality of life in sending societies on the process of incorporation. To test the effects of transnational forces, I ran a simple correlation to measure how the percentage of women with some secondary education in sending societies correlated with the attainment of Latinas in the US and obtained an R-value of 0.5694 , indicating a moderate positive correlation between the two variables.

Table 3. Educational attainment levels of Latina nationals measured by 2010 and 2018 college graduation rates.

\begin{tabular}{|c|c|c|c|c|c|c|}
\hline Latina Nationals & $\begin{array}{l}2017 \\
\text { HDI }\end{array}$ & $\begin{array}{l}\text { Gender } \\
\text { Inequality } \\
\text { Rank }\end{array}$ & $\begin{array}{c}\text { Percentage of Women } \\
\text { with Some Secondary } \\
\text { Education }\end{array}$ & 2010 & 2018 & $\begin{array}{c}\text { Percentage Change } \\
\text { 2010-2018 }\end{array}$ \\
\hline \multicolumn{7}{|l|}{ High HDI } \\
\hline Costa Ricans & 0.798 & 64 & 54 & 62 & 55 & -7 \\
\hline Panamanians & 0.789 & 109 & 73 & 49 & 51 & 2 \\
\hline Cubans & 0.777 & 65 & 87 & 50 & 53 & 3 \\
\hline Mexicans & 0.774 & 76 & 58 & 33 & 40 & 13 \\
\hline Venezuelans & 0.761 & 105 & 72 & 64 & 49 & -15 \\
\hline Ecuadorians & 0.752 & 88 & 52 & 52 & 57 & 5 \\
\hline Peruvians & 0.750 & 83 & 57 & 59 & 62 & 3 \\
\hline Colombians & 0.747 & 87 & 51 & 55 & 50 & -5 \\
\hline Dominicans & 0.736 & 103 & 59 & 47 & 44 & -3 \\
\hline \multicolumn{7}{|l|}{ Medium HDI } \\
\hline Hondurans & 0.617 & 109 & 37 & 30 & 32 & 2 \\
\hline Salvadorians & 0.674 & 91 & 42 & 32 & 37 & 5 \\
\hline Guatemalans & 0.650 & 120 & 38 & 25 & 33 & 8 \\
\hline Nicaraguans & 0.658 & 106 & 48 & 44 & 49 & 5 \\
\hline
\end{tabular}

Note. The HDI data come from the 2018 UN Human Development Report and the 2010 and 2018 enrollment data from Table 302.62 in DES.

Regardless of the limitations of these exploratory findings, it is worth considering a few implications from the early results. First, quality-of-life conditions in sending societies should be taken into account more often when the educational success of various immigrant communities is considered. The dedication of many Latino/Hispanic families is evident in the relative improvements in academic performance in the last two decades despite prevailing instances of bias. However, the legacy of national development still conditions fluctuations in educational success among co-ethnics. Thirdly, academic research may benefit from conducting more within-ethnic comparisons rather than focusing on pan-ethnic research designs. Lastly, considering the increasingly globalized and transnationalized communities in which we reside today, educators would do well in taking exogenous forces into account when formulating policies.

Table 3 shows, at least conceptually, that levels of national development, as measured by the United Nations Human Development Index, may be another condition impacting the range of educational opportunities among Latina students. As expected, immigrant families from societies with high levels of development (HDI) enjoy more access to betterrun schools and early childhood education programs [37]. Even in families who do not have direct access to high-performing schools and programs, students might witness the success of their peers, and this perception may be enough to stimulate their aspirations to further their studies. In addition, having access to better and more educational opportunities means these students might build enough human capital to facilitate their transition once their families migrate [38]. Societies with a higher standard of living also experience higher coefficients of women's independence to pursue professional opportunities. For instance, the UN Human Development Report states that in nations with medium HDI and moderate educational attainment, the percentage of 20-24-year-old women who are married is higher than in countries with high HDI and more elevated college enrollments. 
In his book, Colonialism and Postcolonial Development. Spanish American in Comparative Perspective, James Mahoney [39] demonstrates that despite the turbulent political history that has dominated the region since independence, the pattern of inequality that characterizes Latin American nations has remained relatively consistent. He attributes this configuration to the distinct legacy of colonialism in the region. To this effect, Mahoney [39] concludes, "colonialism not only helped to create the countries of South America; it also sorted them into different positions in the world hierarchy of development" (p. 203). This paper takes Mahoney's assertion one step further to demonstrate the lingering effects of national development stratification on educational outcomes in receiving societies. The sociologist Arthur Stinchcombe [40], along with many historians, recognizes the persistent effects of historical factors when it comes to reproducing social conditions.

Admittedly, the outcome of my research needs to be supported by more evidence before any conclusive findings can be reported with confidence. However, a similar pattern of differential attainment rates manifests itself among Asian students. Students from lessdeveloped Southeast Asian nations do not usually match the educational performance of their counterparts from other parts of Asia. After disaggregating the 2018 scores of Asians and Pacific Islanders, it is evident that the two groups graduated almost the same number of high schoolers (98 and 91\%, respectively). Still, as grades levels increased, disparities within the Asian American community widen from $71 \%$ of Asian college graduates to just 15\% from Pacific Island nations. (NCES, 2018, Table 104. p. 20)

To be sure, many intervening variables often affect the lingering effects of national development on the distribution of educational outcomes. For instance, Table 3 does not show any data about the levels of academic support universities offer Latinas and other students. We cannot possibly know whether these are first-, second-, or third-generation graduates or whether families' education and income levels contributed to success in school. Migration status is also unknown, although we can suppose that South American migrants tend to fall into what is generally categorized as political refugees, which usually consist of the middle class and other professionals fleeing repressive regimes or political upheavals. For these reasons, among others, any conclusions from the data presented in Table 3 must be considered preliminary and received with caution.

\section{Conclusions}

This paper attempted to unravel the complexities of uneven educational opportunities to support the argument that Latinas continue to be genuinely disadvantaged in educational attainment despite their considerable achievement since 2005. Education is vital to secure prosperity in today's post-Fordist globalized economy, but it is also essential because as many migrant families move around in search of more and better educational opportunities, they might encounter conditions that do not meet their expectations, providing a good probability that patterns of assimilation might be altered. As such, education still constitutes a reliable barometer to measure opportunities in multiethnic societies. The demographic estimates published by the latest US Census should alert researchers and policymakers to the necessity and urgency of addressing questions related to the achievement gap in the country. Conditions around the world, primarily the state of sustaining inequality and increasing diversity, enhance the relevance of the evidence presented in this analysis. This is even more relevant when taking into account the transnational dimensions of inequality in domestic communities. Although admittedly preliminary, this paper shows that in addition to the insights from the literature on differential education rates, another consideration of inequality is the legacies of the social context from the societies migrants leave behind.

One relevant implication sustainability policymakers and analysts can draw from these findings is to advocate for more attention and resources to increase the number of students of color who choose to continue their education beyond secondary school. The proposed Sustainable Development Goal 4 promotes inclusive and equitable educational attainment, but it overlooks the challenges posed by the differential attainment rates and 
the association between national development and educational achievement. The literature is quite specific about where to direct this investment to mitigate the educational and quality-of-life legacy associated with levels of national development among Latinas. The literature also demonstrates that the problem goes beyond the cost of higher education, since many fine state institutions offer affordable tuition discounts to state residents in addition to the increased number of aid packages usually available. Unless the educational community recognizes the complexity behind the enduring inequality [41], there is little chance the alarming unequal trend will be revoked any time soon.

Funding: This research was supported by the GR100683 DEAN2952 Professional Development Fund from the College of Arts and Sciences at Santa Clara University. The funders played no role in the design or implementation of the research reported here, and the analysis and conclusions are the authors' alone.

Institutional Review Board Statement: Not applicable.

Informed Consent Statement: Not applicable.

Data Availability Statement: The data supporting my results can be found in the Digest of Educational Statistics. The digest is published by the US Dept. of Education.

Conflicts of Interest: The authors declare no conflict of interest. The funders had no role in the design of the study, in the collection, analyses, or interpretation of data, in the writing of the manuscript, or in the decision to publish the results.

\section{References}

1. Ritchie, S. Elena's Story: Dream on Hold. Kino Border Initiative Newsletter. 2020. Available online: https://www. kinoborderinitiative.org/elenas-story-dreams-on-hold/ (accessed on 12 August 2020).

2. De Brey, C.; Snyder, T.D.; Zhang, A.; Dillow, S.A. Digest of Education Statistics 2019. 2021. National Center for Education Statistics at Institute of Education Sciences. Available online: https:/ / eric.ed.gov/?id=ED611019 (accessed on 1 February 2021).

3. Carnevale, A.; Fasules, M. Running Faster but Still Behind. Georgetown University Center on Education and the Work Force. 2017. Available online: https:/ / eric.ed.gov/?id=ED590640 (accessed on 22 November 2017).

4. Field, K. More Hispanics Are Going to College. The Bad News? They Are Still Behind. The Hechinger Report. 2018. Available online: https:/ / hechingerreport.org/rising-college-rates-spur-hispanic-progress-in-higher-education/ (accessed on 6 August 2020).

5. Krogstad, J.M.; Radford, J. Education Levels of U.S. Immigrants Are on the Rise; Pew Research Center: Washington, DC, USA, 2018.

6. Bustamante, L.N. Educational Levels of Recent Latino Immigrants in the US Reached New Highs as of 2018; Pew Research Center: Washington, DC, USA, 2020; Available online: https://www.pewresearch.org/fact-tank/2020/04/07/education-levels-of-recentlatino-immigrants-in-the-u-s-reached-new-highs-as-of-2018/ (accessed on 6 August 2020).

7. Velez, W. The educational experiences of Latinos in the United States. In Latinas/Os in the United States: Changing the Face of America; Springer: New York, NY, USA, 2008; pp. 129-148.

8. Portes, A.; Rumbaut, R. Immigrant America. A Portrait, 4th ed.; University of California Press: Berkley, CA, USA, 2014.

9. Zarate, M.E. Understanding Latino Parent Involvement in Education Perceptions, Expectations, and Recommendations; The Tomas Rivera Policy Institute: Los Angeles, CA, USA, 2007.

10. Mehta, J.; Davies, S. Education in a New Society; University of Chicago Press: Chicago, IL, USA, 2018.

11. Madrid, M.E. The Latino Achievement Gap. 2011. Available online: https:/ / files.eric.ed.gov/fulltext/EJ955929.pdf (accessed on 6 August 2020).

12. Lopez, M. Latinos and Education. Explaining the Attainment Gap; Pew Hispanic Center: Washington, DC, USA, 2009.

13. Peralta, D.P. Undocumented: A Dominican Boy's Odyssey from a Homeless Shelter to the Ivy League; Penguin: New York, NY, USA, 2015.

14. Pumar, E.S.; Sitsis, A. Educational attainment in a high performing school district: The relative significance of class. Theory Action. 2012, 5, 58-72. [CrossRef]

15. Hornby, G. Parental Involvement in Childhood Education; Springer: New York, NY, USA, 2011.

16. Suarez-Orozoco, C.; Todorava, I.; Louie, J. Making up for Lost Time: The Experience of Separation and Reunification among Immigrant Families. Fam. Process. 2002, 41, 625-643. [CrossRef] [PubMed]

17. Schen, C.R. When Mothers Leave Their Children Behind. Harv. Rev. Psychiatry 2005, 13, 233-243. [CrossRef] [PubMed]

18. Capps, R.; Cardoso, J.B.; Brabeck, K.; Fix, M.; Soto, A.G.R. Immigration Enforcement and the Mental Health of Latino High School Students. The Migration Policy Institute. 2020. Available online: https://www.migrationpolicy.org/research/immigrationenforcement-mental-health-latino-students (accessed on 6 August 2020).

19. Vega, D.; Moore III, J.L.; Miranda, A.H. Who really cares? Urban youth's perception of parental and programmatic support. Sch. Commun. J. 2015, 25, 53-72.

20. Zaloom, C. Indebted: How Families Make College Work at Any Cost; Princeton University Press: Princeton, NJ, USA, 2019. 
21. Alcocer, L.F.; Martinez, A. Mentoring Hispanic students: A literature review. J. Hisp. High. Educ. 2017, 18, 1-9. [CrossRef]

22. Davis, L.; Fry, R. College Faculty Have Become More Racially and Ethnically Diverse, But Remains Far Less so Than Students; Pew Research Center: Washington, DC, USA, 2019; Available online: https://www.pewresearch.org/fact-tank/2019/07/31/uscollege-faculty-student-diversity / (accessed on 31 July 2019).

23. Coles, T. Critical Pedagogy: Schools Must Equip Students to Challenge the Status Quo. The Guardian, 25 February 2014. Available online: https:/ / www.theguardian.com/teacher-network/teacher-blog/2014/feb/25/critical-pedagogy-schools-studentschallenge (accessed on 6 August 2020).

24. Freire, P. Pedagogy of the Oppressed; Continuum Publishing: New York, NY, USA, 1973.

25. Massaro, R. 2021 Silicon Valley Index; Institute for Regional Studies: San Diego, CA, USA, 2021.

26. Sadovnick, A.R.; Coughlan, R.W. Sociology of Education. A Critical Reader, 3rd ed.; Routledge: New York, NY, USA, 2016.

27. Karabel, J.; Halsey, A.H. Power and Ideology in Education; Oxford University Press: New York, NY, USA, 1977.

28. Hussar, B.; Zhang, J.; Hein, S.; Wang, K.; Roberts, A.; Cui, J.; Smith, M.; Mann, F.B.; Barmer, A.; Dilig, R. The Condition of Education 2020; National Center for Education Statistics: Washington DC, USA, 2020. Available online: https://nces.ed.gov/pubsearch/ pubsinfo.asp?pubid=2020144 (accessed on 13 August 2020).

29. Hartocollis, A. Justice Dept. accuses Yale of discrimination in application process. The New York Times, 13 August 2020. Available online: https: / www.nytimes.com/2020/08/13/us/yale-discrimination.html (accessed on 13 August 2020).

30. Nguyen, M.; Bibo, E.W.; Engle, J. Advancing to Completion. Increasing Degree Attainment by Improving Graduation Rates and Closing the Gap for Hispanic Students. The Education Trust. 2012. Available online: https:/ / edtrust.org/wp-content/uploads/ 2013/10/Advancing_Hisp.pdf (accessed on 20 August 2020).

31. Vlaardingeerborek, B.; Ros, L. Educational transition rates and upper secondary students' arithmetical ability in five developing countries. Educ. Stud. Math. 1990, 21, 451-460. [CrossRef]

32. Semega, J.; Kollar, M.; Mohanty, A. Income and Poverty in the United States: 2018; US Census Bureau: Washington, DC, USA, 2020.

33. Rumbaut, R. Children of Immigrants and Their Achievement: The Roles of Family, Acculturation, Social Class, Gender, Ethnicity, and School. In Addressing the Achievement Gap: Findings and Applications; Information Age Publishing: New York, NY, USA, 2005; pp. 23-59.

34. Funk, C.; Parker, K. Women and Men in STEM Often at Odds over Workplace Equity; Pew Research Center: Washington, DC, USA, 2018; Available online: https:/ /www.pewresearch.org/social-trends/2018/01/09/women-and-men-in-stem-often-at-oddsover-workplace-equity/ (accessed on 9 January 2018).

35. Broady, K.; Hershbein, B. Major Decisions: What Graduates Earn over Their Lifetimes. The Hamilton Project. 2020. Available online: https://www.hamiltonproject.org/blog/major_decisions_what_graduates_earn_over_their_lifetimes (accessed on 6 August 2020).

36. Zhang, H. Literature Review on Educational Attainment of Migrant Children in China. Open J. Soc. Sci. 2016, 04, 190-206. [CrossRef]

37. O'Donogue, J. Gastar para Aprender. Un Primer Acercamiento al Gasto en la Infancia Temprana. Available online: http:/ /www. educacionfutura.org/wp-content/uploads/2014/05/Los-Invisibles_estado-de-la-educacion-en-mexico_2014.pdf (accessed on 12 August 2020).

38. Hirschman, A.O. The Passions and the Interests. Political Arguments for Capitalism and Its Triumph; Princeton University Press: Princeton, NJ, USA, 2013.

39. Mahoney, J. Colonialism and Postcolonial Development. Spanish-America in Comparative Perspective; Cambridge University Press: Cambridge, UK, 2010.

40. Stinchcombe, A. Constructing Social Theories; Harcourt Brace: San Diego, CA, USA, 1968.

41. Giddens, A. The Constitution of Society; University of California Press: Berkeley, CA, USA, 1984. 